\title{
ПРОЕКТИРОВАНИЕ И ЭКСПЕРИМЕНТАЛЬНЫЕ ИССЛЕДОВАНИЯ СТАЛЕФИБРОБЕТОННОЙ ПЛИТЫ ПЕРЕКРЫТИЯ
}

Сурьянинов Н. Г., д.т.н., проф

Корнеева И. Б., к.т.н., дои.

Крыюжановская А. Н., магистр

Украина, Одесса, Одесская государственная академия строительства и архитектуры

DOI: https://doi.org/ 10.31435/rsglobal_ws/30112018/6230

\section{ARTICLE INFO}

Received: 10 September 2018

Accepted: 23 November 2018

Published: 30 November 2018

\section{KEYWORDS}

floor slab,

fiber concrete,

dispersed reinforcement, experiment, carrying capacity, crack.

\begin{abstract}
In the work, the design of the floor slab with five voids of steel fiber concrete, similar to a serial reinforced concrete slab, is proposed. Both plates are calculated in accordance with the regulations on the first and second limiting states. For experimental studies, a series of plates was made, each of which was tested before destruction. Scaling was used for all the plates, taking into account the design standards and technological capabilities of the laboratory.

The loading of structures during testing was carried out in steps. Each step was $10 \%$ of the control load when checking the bearing capacity and crack resistance and $20 \%$ of the control load when checking the rigidity of structures. As a result of tests, the values of stresses and deflections were obtained as in theoretical calculations, the stresses in the concrete and steel fiber concrete slabs differ only slightly, and the deflections, especially up to $60 \%$ of the breaking load, differ several times, which confirms the much slower crack opening in the steel fiber concrete slabs. This suggests that at loads corresponding to the operational level, cracks will not open. The use of steel fiber concrete with preservation of linear reinforcement for the manufacture of hollow-core slabs allows to improve their characteristics, first of all - bearing capacity and crack resistance.
\end{abstract}

Citation: Сурьянинов Н. Г., Корнеева И. Б., Крыжановская А. Н. (2018) Proektirovanie i Eksperimentalnie Issledovaniya Stalefibrobetonnoi Pliti Perekritiya. World Science. 11(39). doi: 10.31435/rsglobal_ws/30112018/6230

Copyright: (C) 2018 Сурьянинов Н. Г., Корнеева И. Б., Крыжановская А. Н. This is an openaccess article distributed under the terms of the Creative Commons Attribution License (CC BY). The use, distribution or reproduction in other forums is permitted, provided the original author(s) or licensor are credited and that the original publication in this journal is cited, in accordance with accepted academic practice. No use, distribution or reproduction is permitted which does not comply with these terms.

Введение. Применение железобетонных пустотных плит в промышленном и гражданском строительстве носит массовый характер, методы их проектирования и расчета хорошо известны, и регламентируются нормами [1 - 3]. На малых и средних пролетах используется обычная стержневая арматура, на больших - предварительно напряженная. Наиболее востребованными являются плиты средних пролетов, но и они имеют недостатки это возможность образования отслоений, трещин и других деформаций при достаточно небольших нагрузках, хрупкое разрушение при перегрузке. Для устранения этих недостатков представляется возможным использовать в производстве пустотных плит сталефибробетон.

Дисперсное фибровое армирование позволяет в значительной мере компенсировать главные недостатки бетона - низкую прочность на растяжение и хрупкость разрушения, а также снижает усадку и ползучесть. Сталефибробетон выгодно отличается от традиционного бетона, имея в несколько раз более высокие по сравнению с ним прочность на растяжение и срез, ударную и усталостную прочность, трещиностойкость и вязкость разрушения, 
морозостойкость, водонепроницаемость, сопротивление кавитации, жаропрочность и пожаростойкость. Это обеспечивает его высокую технико-экономическую эффективность при применении в строительных конструкциях. Исследования в этом направлении проводились [4, 5], но в результате была предложена кардинально иная конструкция плиты, что при промышленном производстве требует замены оборудования.

Постановка проблемы. Опыт проектирования, изготовления и эксплуатации сталефибробетонных конструкций в различных областях строительства показал высокую технико-экономическую эффективность их применения [6, 7].

Наиболее эффективно могут быть использованы следующие технические преимущества по сравнению с обычным железобетоном:

- повышенные трещиностойкость, ударная вязкость, износостойкость и морозостойкость;

- возможность использования тонкостенных конструкций;

- снижение трудозатрат на арматурные работы;

- возможность применения более производительных приемов формования конструкций.

Для изгибаемых конструкций из железобетона наибольшей проблемой является возможность раскрытия трещин и хрупкого разрушения, чего можно избежать, применяя сталефибробетон вместо обычного бетона [8 - 10].

Замена обычного бетона на сталефибробетон позволяет также снизить объем стержневой арматуры.

Для решения этих задач необходимы в первую очередь экспериментальные исследования, поскольку аналитический расчет не позволяет учесть все особенности работы конструкции, а компьютерное моделирование с последующим численным анализом могут служить проверкой результатов экспериментальных исследований.

Целью данной работы является проектирование железобетонной пустотной плиты перекрытия с дисперсным армированием стальной фиброй с последующими экспериментальными исследованиями.

Результаты исследования. Была разработана конструкция сталефибробетонной многопустотной плиты перекрытия, аналогичная ПК 30.12-8 серии 1.141-1 (рис. 1). Отличие серийной и сталефибробетонной плит в количестве пустот $(6-$ в серийной, 5 - в сталефибробетонной) и добавлении стальной фибры в бетонную смесь для изготовления плиты предложенной конструкции.

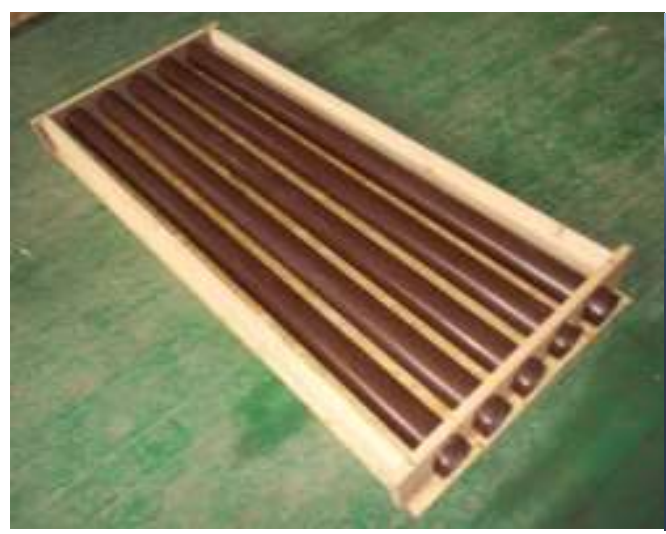

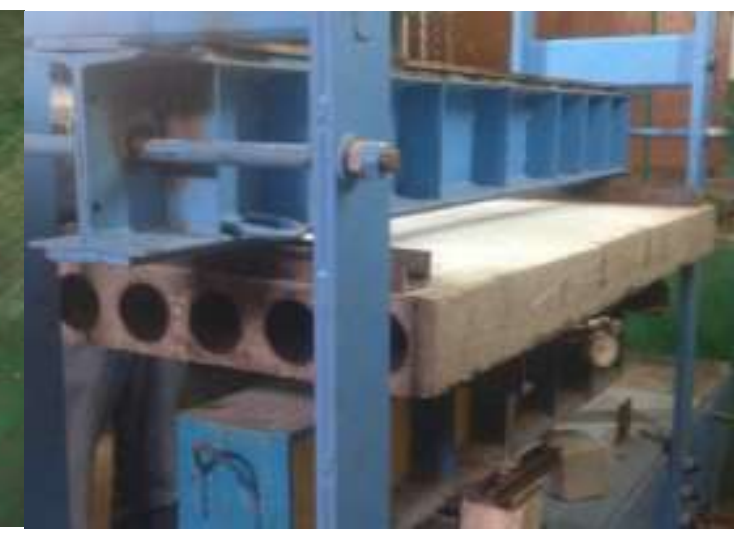

б

Рис. 1. Конструкция плиты из сталефибробетона: $а$ - опалубка; б - готовая плита

Обе плиты рассчитаны в соответствии с нормативными документами [1 - 3] по первому и второму предельным состояниям, нагрузка принята одинаковая.

Условия прочности:

по первому предельному состоянию:

$$
F \leq F_{u}
$$

где $F$ - расчетное усилие, равное возможному максимальному усилию в сечении элемента при самой невыгодной комбинации расчетных нагрузок;

$F_{u}$ - расчетная несущая способность сечения;

по второму предельному состоянию:

$$
A \leq A_{u}
$$


где $A$ - прогибы от нормативной нагрузки; элемента.

$A_{u}$ - предельные значения прогибов, установленные для данного конструктивного

Так как за счет удаления одной из пустот вес плиты увеличился, то введение фибры несущественно сказалось на результате расчета на прочность. Расчет же на раскрытие трещин показал, что при равных нагрузках трещины в сталефибробетонной плите практически не раскрываются, хотя момент начала трещинообразования не изменился.

Для экспериментальных исследований была изготовлена серия плит, каждая из которых испытывалась до разрушения. Для всех плит использовалось масштабирование с учетом норм проектирования и технологических возможностей лаборатории.

При укладке бетонной смеси в форму были соблюдены следующие требования:

- укладка в форму бетонной смеси производилась не позднее 30-45 мин. от момента ее приготовления;

- распределение бетонной и фибробетонной смесей по формам было равномерным;

- не допускалось попадание в форму комков схватившегося бетона, крупных включений щебня, посторонних предметов;

- не допускалось смещение диафрагм, пустотообразователей и проставок.

В соответствии с нормативными документами, было учтено, что при выполнении работ по извлечению съемной оснастки и отделке отформованных плит не допускается:

- разрыхление бетонной смеси вокруг пустотообразователей и диафрагм с целью облегчения их извлечения;

- приложение новой бетонной смеси на место отвалившихся при извлечениии пустотообразователей и диафрагм кусков;

- заделка пустот вокруг проволок на торцах плит и заглаживание торцов.

При проведении статических испытаний загружение исследуемых конструкций внешней нагрузкой осуществлялось постепенно, без рывков и ударов, чтобы исключить влияние сил инерции. Также была обеспечена стабильность нагрузок, их постоянство во времени на протяжении всего периода проведения испытаний.

Перед началом испытаний была проделана предварительная подготовка:

- изготовлены и смонтированы нагрузочные приспособления;

- установлены измерительные приборы, подмости и ограждения;

- выполнены работы по предварительному загружению испытательной конструкции.

Предварительное загружение является контрольным этапом испытания. На данной стадии проверяется надежность нагрузочных приспособлений, крепление приборов и испытываемой конструкции, правильность показаний установленных приборов. Интенсивность предварительного загружения принималась равной величине первой ступени нагрузки, предусмотренной программой испытаний.

Загружение конструкций при испытании осуществлялось ступенями. Каждая ступень составляла $10 \%$ контрольной нагрузки при проверке несущей способности и трещиностойкости и $20 \%$ контрольной нагрузки при проверке жесткости конструкций. На каждой ступени конструкцию выдерживали не менее 10 минут. После приложения каждой ступени нагрузки производился тщательный осмотр конструкции для выявления как вновь появившихся повреждений, так и степени развития уже имеющихся. Запись показаний приборов на каждой ступени осуществлялась после 10-и минутной выдержки приложенной нагрузки. Отсчеты по всем измерительным приборам производились быстро, чтобы их показания соответствовали одному и тому же деформированному состоянию испытываемой конструкции. Показания приборов, схемы их расположения, данные замеров трещин заносились в журнал испытаний. 


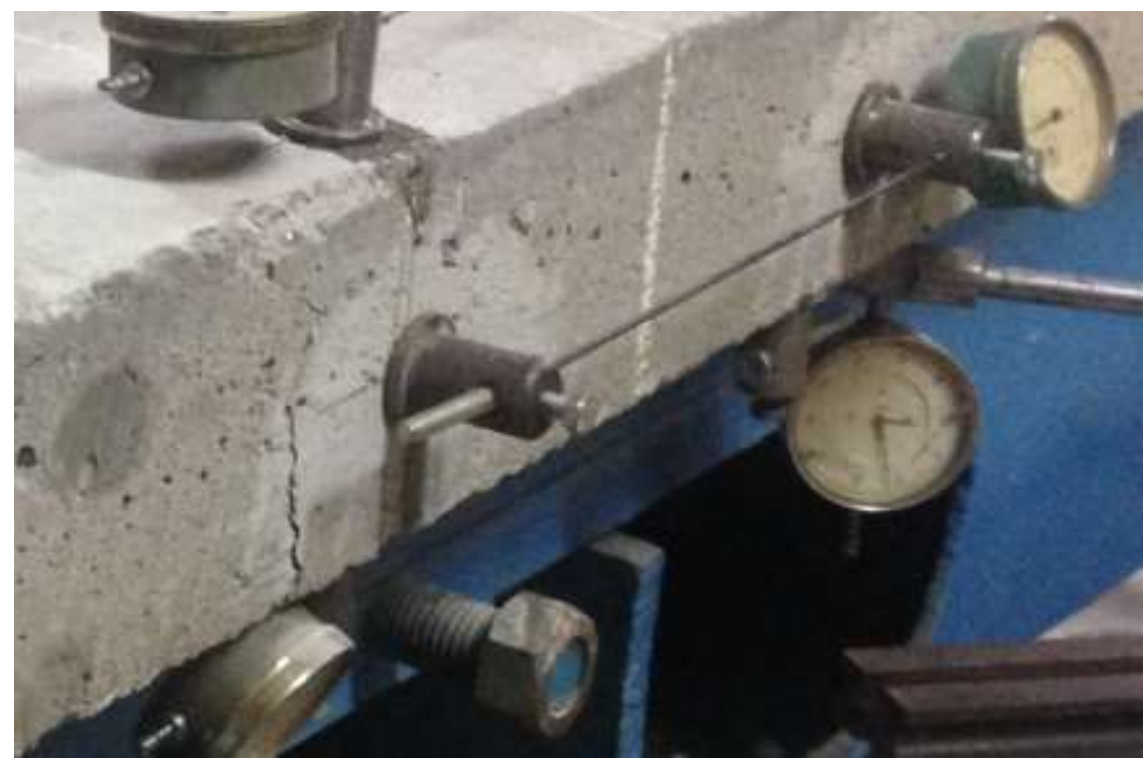

Рис. 2. Трещчина, образовавшаяся в процессе испьтаний плиты

Была разработана и реализована программа испытаний с учетом комплексного и обычного армирования плит. Параллельно были изготовлены кубы и призмы, которые твердели в одинаковых условиях с конструкциями. Для определения физико-механических характеристик бетона экспериментальных образцов, в каждой серии испытаны шесть контрольных кубов размером 100x100x100 мм и три призмы размером 100x100x400 мм, изготовленных при формовании железобетонных и сталефибробетонных плит. Испытания контрольных образцов выполнены по действующим нормам [11 - 13].

Для корректной оценки результатов материалы должны соответствовать характеристикам, заложенным в серийной плите, в частности, бетон должен иметь марку C16/20, что и было установлено по результатам испытаний контрольных образцов. Из технологических соображений размеры экспериментально исследуемых плит пропорционально уменьшены в два раза.

График зависимости деформаций от нагрузки для плит из бетона и фибробетона показан на рис. 3 .

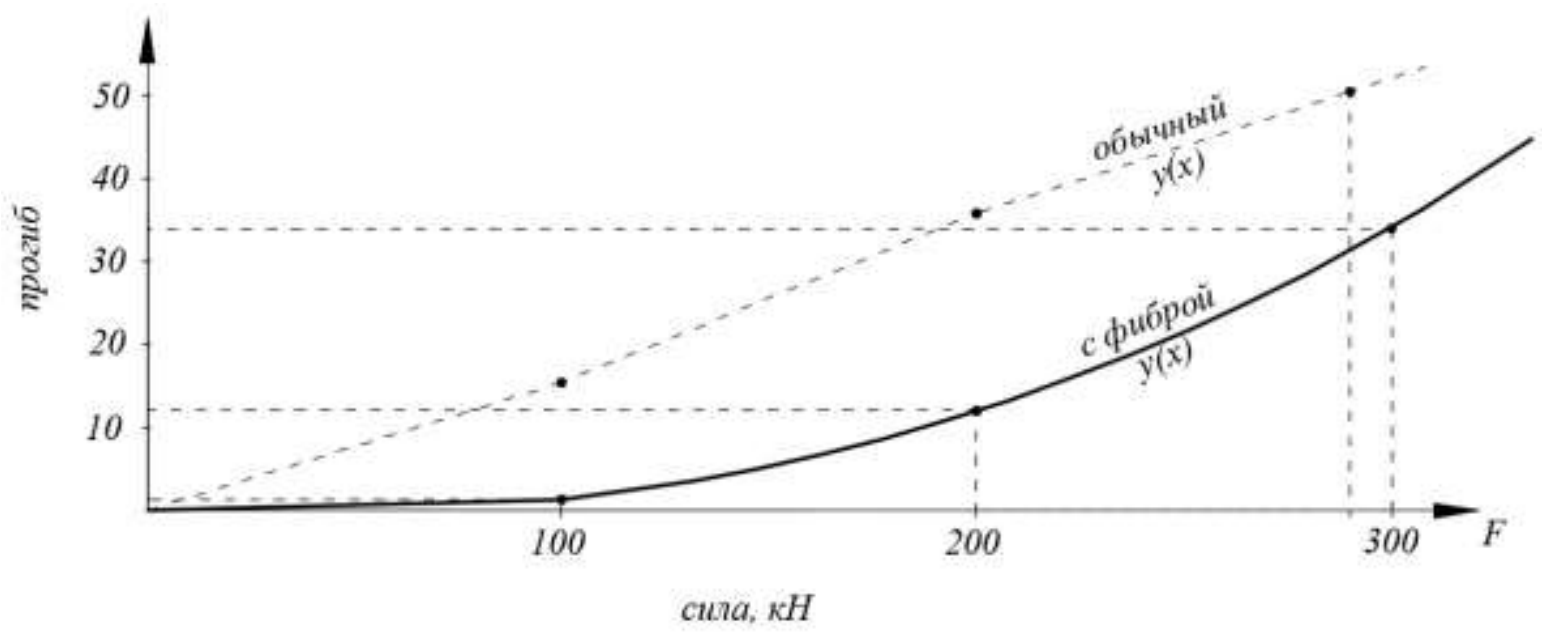

Рис. 3. График зависимости деформаџий от нагрузки для плит из бетона и фибробетона

Результаты сравнительного анализа прогибов и развития трещин приведен в табл. 1. 
Таблица 1. Сравнительный анализ прогибов и развития трещин

\begin{tabular}{|c|c|c|c|c|c|c|c|c|c|}
\hline$F / F_{\text {разуи }}$ & 0,1 & 0,2 & 0,3 & 0,4 & 0,5 & 0,6 & 0,7 & 0,8 & 0,9 \\
\hline$f_{c ф б} / f_{\text {жб }}$ & 0,03 & 0,05 & 0,07 & 0,12 & 0,19 & 0,26 & 0,41 & 0,53 & 0,61 \\
\hline
\end{tabular}

Выводы. В результате испытаний получены значения напряжений и прогибов. Как и в теоретических расчетах, напряжения в бетонной и сталефибробетонной плитах отличаются несущественно, а прогибы, особенно до нагрузки $60 \%$ от разрушающей, отличаются в несколько раз (рис. 3), что подтверждает гораздо более медленное раскрытие трещин в сталефибробетонной плите. Это позволяет утверждать, что при нагрузках, соответствующих эксплуатационному уровню, трещины раскрываться не будут. Использование сталефибробетона с сохранением линейного армирования для изготовления многопустотных плит перекрытия позволяет улучшить их характеристики, в первую очередь - несущую способность и трещиностойкость.

\section{ЛИТЕРАТУРА}

1. ДБН В.2.6-98:2009. Бетонні та залізобетонні конструкції. Основні положення. - К.: Мінрегіонбуд України, 2011. - $73 \mathrm{c}$.

2. EN 1992:2009«Железобетонные конструкции. Проектирование, расчеты, параметры»

3. ДБН В.1.2-2:2006. Система забезпечення надійності та безпеки будівельних об'єктів. Навантаження і впливи. Норми проектування. - К.: Мінбуд України, 2006. - 77 с.

4. Талантова К.В. Сталефибробетон с заданными свойствами и строительные конструкции на его основе: дисс. ... д-ра техн. наук / К.В. Талантова. - Барнаул, 2013. - 287c.

5. Капустин Д.Е. Прочностные и деформативные характеристики несъемной сталефибробетонной опалубки как несущего элемента железобетонных конструкций: дисс. ... канд. техн. наук / Д.Е. Капустин. - М., 2015. - 211 с.

6. Блещик, Н.П. Физико-механические и технологические свойства сталефибробетона, особенности применения и перспективы развития сталефибробетонных конструкций / Н.П. Блещик, И.В. Коваль // Третий международный симпозиум: «Проблемы современного бетона и железобетона». - 2011.

7. Павленко В.И., Арончик В.Б. Свойства фибробетона и перспективы его применения: аналитический обзор / Рига, ЛатНИИ, 1978. - 57c.

8. Гетун, Г. В. Экспериментально-теоретические исследования изгибаемых железобетонных конструкций, усиленных в растянутой зоне слоем сталефибробетона: автореф. дис. ... канд. техн. наук / Г. В. Гетун. - Киев, 1983. -20 с.

9. Смирнов Д.А. Упругость и ползучесть сталефибробетона: автореф. дисс. ... канд. техн. наук / Д. А. Смирнов. - СПб., 2011. -20 с.

10. ДСТУ-Н Б В.2.6-78:2009. Конструкції будинків і споруд. Настанова з проектування та виготовлення сталефібробетонних конструкцій. - К.: Мінрегіонбуд України, 2009. - 46 с.

11. EN 14845-2:2006 Test methods for fibers in concrete. Effect on concrete.

12. BS EN 12390-3:2009 Testing hardened concrete. Compressive strength of test specimens.

13. ДСТУ Б В.2.7-214:2009 Строительные материалы. Бетоны. Методы определения прочности по контрольным образцам. - К.: Мінрегіонбуд України, 2010. - 43 с. 